determining oxygen evolution at anodic sites on the oxide.

The final session of the meeting, with Dr. S. Schuldiner in the chair, was concerned with the doublelayer and adsorption at electrodes. The correlation between double-layer capacity and kinetics of electrode processes was examined in a paper by Drs. M. Breiter and P. Delahay (Louisiana State University), and Drs. R. S. Hansen and D. A. Hickson (Iowa State College) presented some interesting results on the apparent dependence on frequency of the capacity of the double-layer; relaxation times for water in the double-layer as high as $10^{-2}$ sec. were deduced. This occasioned some discussion, since it was pointed out that even in the ice lattice, where the water is strongly bound, the relaxation time is much smaller (about $10^{-6}$ sec.). Dr. R. Parsons (University of Bristol) read the paper by Prof. A. Frumkin (Academy of Sciences, Moscow) on the influence of surface-active anions on the electro-reduction of persulphate anions at negative potentials ; the acceleration of the reduction of $\mathrm{S}_{2} \mathrm{O}_{8}{ }^{2}$ - which was observed in the presence of surface-active anions was explained in terms of their effect on the potential $\left(\psi_{1}\right)$ at the outer Helmholtz plane in the double-layer. Specific effects of cations on the kinetics required that a local fluctuating $\psi_{1}$-potential due to interaction of the adsorbed anions with cations in the double-layer be considered. A general thermodynamic analysis for the determination of heats of adsorption in ionic systems by electrocapillary studies was given in a paper by Dr. R. Parsons and results obtained for the isotensile heats of adsorption of potassium iodide at mercury were discussed. The meeting concluded with two papers describing the adsorption of hydrochloric acid and aromatic aminium salts at mercury by the electrocapillary method (Drs. E. Blomgren and J. O'M. Bockris, University of Pennsylvania) and the adsorption of methylene blue at mercury by collecting a large number of mercury drops which had fallen through the solution and analysing for the dye carried down in the double-layers of the drops (Drs. J. M. Los and C. K. Tompkins, University of New Brunswick). Some results from studies on the direct determination of adsorption of organic ions at solid metals were presented by Dr. B. E. Conway and Mr. R. G. Barradas in discussion.

Most of the papers presented at the meeting will be published early in 1959 in the Canadian Journal of Chemistry.
B. E. Conway

\title{
EAST MALLING RESEARCH STATION
}

\section{ANNUAL REPORT}

$\mathrm{T}$ HE annual report of East Malling Research Station for $1957 *$ contains some important research findings. A new semi-dwarfing apple rootstock, $M 26$, is described by W. S. Rogers; it is intermediate in vigour between $M \mathrm{IX}$ and $M$ VII, and so fills a unique place. The elimination of virus from strawberry clones by heat therapy increased the fruit yield of several varieties, though the crop ripened later, and was more prone to Botrytis rot than untreated plants. In Early Cambridge and Rearguard, however, there was excessive vigour and a decrease in yield (W. S. Rogers and Muriel G. Fromow). Rooting and growth of root cuttings from the apple rootstock Crab $C$ declined with increasing age of establishment of the parent plant, according to results obtained by $R$. J. Garner and E. S. J. Hatcher. Raspberry breeding work, by R. L. Knight and Elizabeth Keep, is now mainly concerned with the introduction of resistance to the virus vector $A m p h o r o p h o r a r u b i$ and to cane spot and Botrytis, while interspecific hybrids are being sought between black-currant and gooseberry. The apple breeding work of H. M. Tydeman shows progress towards a late-flowering variety which will be resistant to scab and mildew.

Two papers in the physiological section show that, in the British climate, temperature is perhaps the most important factor in fruit growth. C. R. Hancock and H. W. B. Barlow show that growth-rate of Crab $C$ shoots was related to temperature and day-length, though the final internode length was less dependent on temperature and had little relation with the daily period of light. The same authors found that the

* Kent Incorporated Society for Promoting Experiments in Horticulture. Annual Report of East Malling Research Station, 1st October 1956, to 30th September, 1957. (Forty-flfth year.) Pp. Xxv +173 . 178. $6 d . ; 2.50$ dollars. effects on leaf growth of a summer gale in 1956 were mainly due to the fall in temperature. D. H. Maggs has compared growth of the rootstocks $M$ II and $M$ XVI with differences in time of leaf-break eliminated; the former produced more stem and the latter more root for plants of the same weight. $M$ II had a smaller increase in weight produced per gram of leaf than $M$ XVI.

Symptoms of magnesium deficiency in apple rootstocks can best be eliminated by foliar spraying with Epsom salts. Elsie M. Ford shows that this method is better than soil application and that it is not enough merely to remove the symptoms, for three sprays are necessary to bring increased vigour.

The virus disease known as little cherry causes serious damage in North America, and now A. F. Posnette and R. Cropley have reported it in Great Britain. G. W. F. Sewell and J. F. Wilson report another new trouble in that some common hop garden weeds have been found susceptible to the 'progressive' strain of the hop wilt fungus Verticillium albo-atrum. There were earlier indications that the hop virus 'nettlehead' was in some way linked with nickel content of the plant. J. T. Legg and P. J. Ormerod find that the symptoms of nickel toxicity and of nettlehead are distinct, though presence of the virus is associated with higher contents of some heavy metals than are found in healthy plants. R. S. Pitcher shows that the life cycle of the currant leaf midge Dasyneura tetensi varies considerably from year to year. This brings difficulties of timing control measures and demonstrates the necessity for more persistent toxicants. A study of Blepharidopterus angulatus by R. C. Muir is mainly an evaluation of the capture-recapture method of estimating orchard insect populations. Phytotoxicity studies by A. H. M. Kirby and Margery Bennett show that a number of 
acaricides are safe to use on the varieties of black currant and plum used for test. On the other hand, phenyl mercury chloride caused direct damage to pears in each season, irrespective of weather conditions.

The report contains the text of the Amos Memorial Lecture by F. C. Bawden on viruses and virus diseases -a most useful general review. It has also papers on methods of recording, sampling and experiment.
There is a detailed paper on soil management effects on a number of chemical and physical properties of the soil (J. E. Goode and G. C. White) the practical implications of which are discussed in one of the four bulletins for fruitgrowers. A review, however, should lay a train of anticipation leading to the detail of the report itself. It is a current guide to the enlarging horizon of the application of science to the culture of fruit.

\section{NEW HYDROXYAMINO-ACIDS IN PLANTS AND THEIR IDENTIFICATION}

\section{Hydroxyvaline in Kalanchoe daigremontiana}

TrHE first application of two-directional paper 1 chromatography to the investigation of soluble nitrogen compounds in plants was reported in Nature in $1947^{1}$, and paved the way for the recog. nition of many new free amino-compounds in plants. By the application of the new techniques, the list of naturally occurring amino-acids became rapidly extended, for hitherto the emphasis had been upon the demonstration, in the free state, of the protein amino-acids and of the amides, asparagine and glutamine. The course of these discoveries has been summarized in a series of reviews ${ }^{2}$ which show the unexpected range of structure which natural amino; and imino-acids display.

The hydroxyamino-acids represent a special category of compounds which have been largely revealed by chromatographic methods, and, as will be seen, the final identification of these substances presents special difficulties and problems.

Prior to the development of paper chromatography, serine and threonine were the only non-phenolic hydroxyamino-acids known with certainty to occur widely distributed and free in Nature. Hydroxyproline and a hydroxylysine of uncertain structure were known in collagen but not known free in plants. Reports of the presence of $\beta$-hydroxyvaline ${ }^{3}$ and $\beta$-hydroxyglutamic acid ${ }^{4}$ remained unconfirmed and eventually proved to be erroneous ${ }^{5}$. Since the application of chromatographic methods, the following hydroxyamino-acids have been found in plants: allohydroxy-L-proline ${ }^{6}$; hydroxy, methylproline ${ }^{7}$; 5 -hydroxypipecolic acid ${ }^{8} ; 4$ (or 3)-hydroxypipecolic acid $^{9}$; homoserine ${ }^{10}$; $\gamma$-hydroxyglutamic $\operatorname{acid}^{11}$; dihydroxyglutamic $\operatorname{acid}^{12} ; \gamma$-hydroxy, $\gamma$ methylglutamic acid ${ }^{8} c ; \alpha$-amino, $\gamma$-hydroxypimelic $\operatorname{acid}^{13} ;$ and $\alpha, \varepsilon$-diamino, $\beta$-hydroxypimelic acid (tabtoxinine $)^{14}$. However, only in the case of allohydroxy-I-proline ${ }^{6}$ has the evidence for these new amino-acids been brought to completion by the synthesis of the compound in question followed by the resolution of the appropriate stereoisomer and the critical comparison, by appropriate physical and chemical methods, of the natural and synthetic products. In one difficult case, involving three centres of asymmetry, the amino-acid in question (tabtoxinine) on synthesis ${ }^{15}$ was found to have a structure different from that first assigned (Braun, A., private communication). The final identification of new compounds with one or more centres of asymmetry, therefore, should include their stereoisomeric configuration; and this being so, more readily applicable methods of optical resolution are needed so that the final identification of these new substances need not lag so far behind their recognition as at present.

Information in both parts of this contribution will extend the general recognition of compounds of this type to include $\gamma$-hydroxyvaline and $\mathrm{O}$-acetylhomoserine.

Hydroxyvaline was first recognized as an unidentified, ninhydrin-reactive spot on paper chromatograms of an alcohol-soluble extract of crowngall tumours from Kalanchoe daigremontiana ${ }^{16}$ and was described as 'Unknown No. 75 ' in a review ${ }^{2 b}$. Subsequent studies showed it to be present in leaves and stems also, but, as yet, only in this single species of Kalanchoe. The substance is not found in $K$. beharensis, longiflora, sexangularis, marmorata, tomentosa, verticillata, gastonis-bonieri or pinnata, nor has it been detected in the many other species of plants which have been examined in this laboratory chromatographically.

On hydrolysis of crude extracts, unknown 75 partially disappears with the concurrent appearance of a second unknown, No. 78, and glutamic acid. The position of Nos. 75 and 78 on a chromatogram are shown in Fig. 1. This preliminary result was first interpreted to mean that two unknown amino-acids occupied identical positions on the chromatograms, and that only unknown No. 75 broke down to give No. 78, while the acid-stable material in the same position as No. 75 was assigned the number 76 .

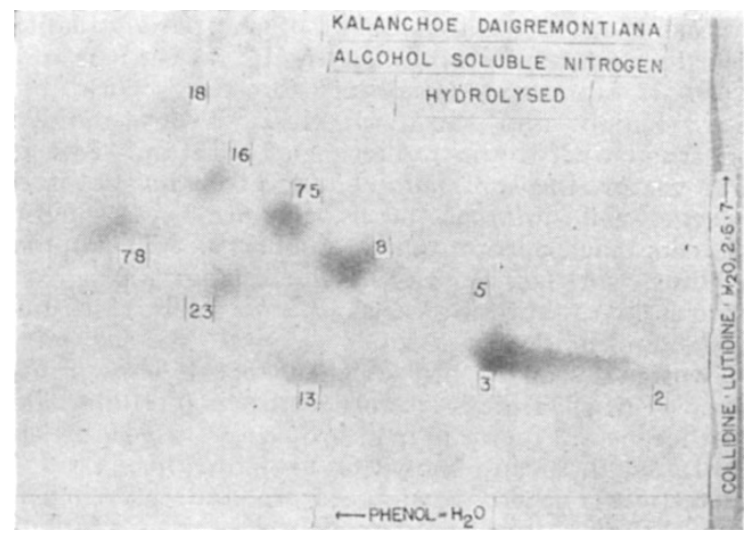

Fig. 1. Two-directional chromatogram, treated with ninhydrin, of the soluble compounds of Kalanchoe daigremontiana (copied from an original photograph in colour).

Numbered key to amino-acids: 2, aspartic acid; 3, glutamic acid; 5, glycine; 8 , alanine; 13 , arginine; 16 , valine; 18 , leucines; $23, \gamma$-aminobutyric acid; 75 and $78, \gamma$-hydroxyvaline and its lactone, respectively. (Nos. 75 and 78 react violet with ninhydrin) 